\title{
Investigating the Effect of Second Language Learning on the Acquisition of a Third Language Rhythm Pattern \\ Carissa Diantoro ${ }^{1,2}$ \\ 'University of Oregon, ${ }^{2}$ Department of Linguistics
}

\section{Introduction}

Language rhytnm arıses trom the language-specific timing of syllables. Languages are classified into 3 main groups: syllable-timed, stress-timed, and mora-timed.

Adult language learners acquire rhythm more easily when a second language (L2) is in the same rhythm class as the native language (L1). Are language transfer effects also evident in third language (L3) learning?

English is a stress-timed. French and Indonesian are syllable-timed. We tested whether English-speaking learners of French would reproduce Indonesian sentence more accurately than English-speaking students who had no college-level language training.

\section{Research Question}

Will training in an L2 with a similar rhythm to an L3 help the acquisition of that L3?

\section{Methods}

Stimuli: A native speaker of Indonesian and a native speaker of French produced 5 sentences for the study. Sentence were controlled for length (810 syllables ea.) and syntactic complexity.

Participants: 12 UO undergraduate students. Half had no college-level language (English-only); half had 2 years of college-level French.

Procedure: Participants listened to and repeated each sentence they heard 10x. Stimulus presentation was blocked by language and randomized within block.

Measurement: All 10 repetitions of Indonesian from the 12 participants were acoustically segmented. Interval durations were extracted to calculate articulation rate and 3 different rhythm metrics: proportion of vowel (\%V); coefficient of variation of consonant $(\Delta \mathrm{C})$, and vowel $(\Delta \mathrm{V})$ duration.

\section{Results}

Summary: Measures of articulation rate, $\Delta C$ and $\Delta V$ varied systematically by group. $\% \mathrm{~V}$ did not. The direction of the group effect was unexpected. Repetition was not significant.
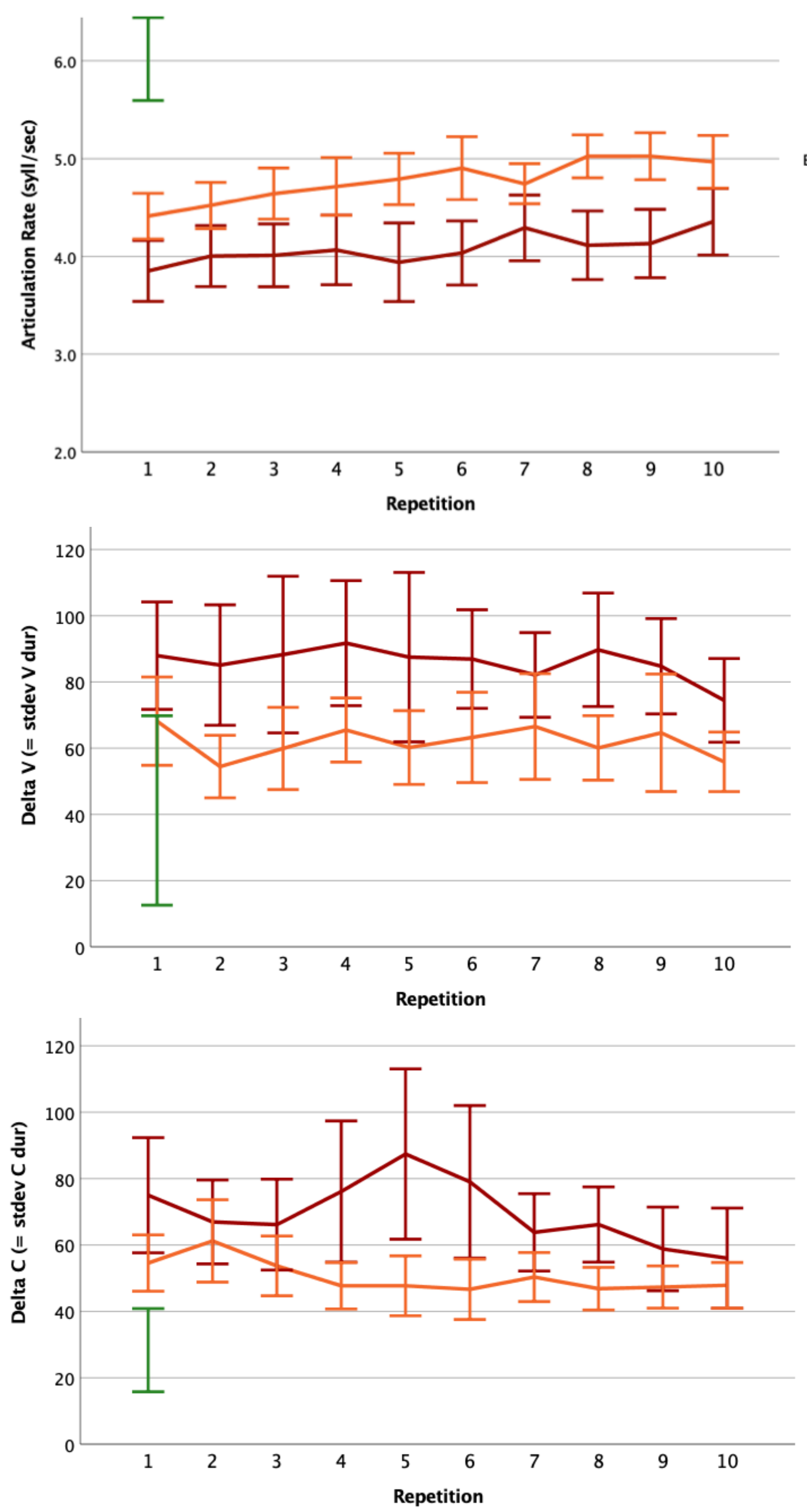

Speaker

I
I Eng+French
I Eng only
I Native stim Error Bars: $95 \%$ C Speaker
I Eng+French
I Eng only
I Native stim Error Bars: $95 \% \mathrm{Cl}$

\section{Discussion}

French L2 learners produced sentences that were less similar to the target syllable-timed $\mathrm{L} 3$ sentences compared to English-only speakers. This may be an effect of language interference (De Bot \& Jaensch, 2015), or it may indicate that all learners produce syllable-timed-like rhythm patterns during early stages of acquisition (Ordin \& Polyanskaya, 2015).

Our next step is to analyze the French sentences to distinguish between the given explanations and to ensure that the French L2 learners were indeed more proficient in a language they are learning compared to English-only speakers.

We also plan to recruit $L 2$ learners of a stress-timed language (i.e., German) to determine if their production of Indonesian sentences differs from the other groups. This will further address our research question, and the explanation from interference or universal pathways in rhythm acquisition

\section{References}

Antoniou, M., Eric, L., Ettlinger, M., Wong, P. (2015). The bilingual advantage in phonetic learning. Bilingualism: Language and Cognition, 18(4), 683-695.

doi:10.1017/S1366728914000777

- Aoyama, K., \& Guton, S. G. (2007). Prosody in second language acquisition: Acoustic analyses of duration and Fo range. In Language Experience in Second Language Speech Best, C. T. (1995). A direct realist view of cross-language speech perception. In W. Strange
(ed.), Speech perception and linguistic experience: Issues in cross-language research (pp. 171-204). Timonium, MD: York Press,

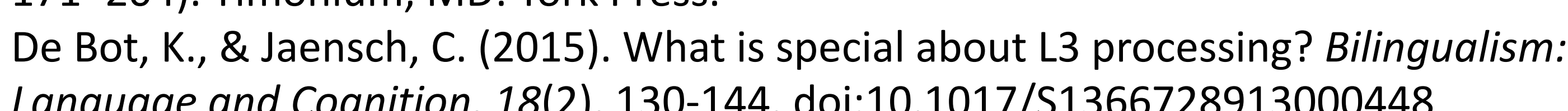
Language and Cognition, 18(2), 130-144. doi:10.1017/\$1366728913000448
Dupoux, E., Pallier, C., Sebastian, N., \& Mehler, J. (1997). A Destressing “Deafness” in - French? Journal of Memory and Language, 36, 406-421. Speaker
I Eng+French
I Eng only Error Bars: $95 \% \mathrm{Cl}$ quantity by native speakers of Spanish, English and Estonian. Journal of Phonetics, 30, 229Ordin, M. \& Polyanskaya, L. (2015)

Acquisition of speech rhythm in a second language by

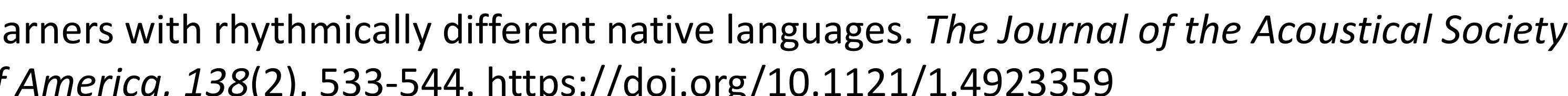

-
sgnal. Cognition, 73(3), 265-292. https://doi. org/10.1016/S0010-0277(00)00101-3

\section{Acknowledgments}

This study would not have been possible without Dr. Melissa Redford's guidance. The work was conducted in the Speech \& Language Lab at the Spoken Language Research Laboratories. 